\title{
ducação em Direitos Humanos: local da diferença
}

Aura Helena Ramos

Universidade do Estado do Rio de Janeiro

Neste artigo, assumindo que $D i$ reitos Humanos e escola são construções discursivas que a hegemonia moderna universalizou, abordamos o processo de constituição curricular de Educação em Direitos Humanos (EDsHs) nos valendo do desafio de ressignificação de Direitos Humanos, o que exige que a questão seja situada no contexto das preocupações relativas ao espaço da diferença no mundo contemporâneo.

Abordamos o processo instituinte do currículo de EDsHs no Brasil, ressaltando, como elementos nucleares dessa aproximação, a percepção das tensões universal/particular e igualdade/diferença, como focos centrais da análise do material empírico produzido.

Destacamos para análise um conjunto de textos voltados à formação 
continuada de educadores e à formulação de diretrizes curriculares de EDsHs produzidos em razão de um projeto implementado nacionalmente, sob a coordenação da Pró-reitoria de Extensão da Universidade Federal da Paraíba (UFPB), com apoio e financiamento do Ministério da Educação (MEC).

É um trabalho que busca elementos para a compreensão do modo como a diferença se articula e constrói consensos no processo de luta hegemônica de constituição do currículo de EDsHs.

\section{Direitos Humanos universais: localismo globalizado em questão}

A questão do estabelecimento de direitos, lato sensu, é tão antiga quanto a própria história da humanidade, que sempre se defrontou com a necessidade de definir princípios reguladores das relações sociais, identificando limites aceitáveis, estabelecendo normas formais/explícitas ou informais/implícitas e definindo formas de controle para a convivência em sociedade.

Considerando características do mundo contemporâneo, como a internacionalização da economia, o aumento radical da mobilidade espaço-temporal, a generalização da configuração multicultural das populações dos diferentes países, entre outras, veremos que os esforços pela instituição e explicitação dessas abordagens, conceitos e normas tornam-se tarefa cada vez mais complexa diante da pluralidade de interesses, visões de mundo, localidades que é necessáro envolver.

Nesse quadro, situa-se o discurso dos Direitos Humanos como estratégico, o que, especialmente desde a criação da Organização das Nações Unidas
(ONU), há 60 anos, destaca a articulação pelo estabelecimento de consensos internacionais com base na enunciação da universalidade dos seus temas.

Idealizada no âmbito da contingência dramática do período pós-Segunda Guerra Mundial, a ONU assumia o desafio de reconstrução dos Direitos Humanos (Piovesan, 2006), tomando para si a definição de princípios que pudessem ser adotados por diferentes nações e, por encarnarem moralidade, ética e ideologia passíveis de serem assumidas universalmente ou, como ainda hoje alguns advogam, que fossem portadores de validade universal. Um dos principais instrumentos desse esforço foi a Declaração Universal dos Direitos Humanos, texto que conserva da tradição moderna a certeza de que o acesso à cultura europeia, seus valores, sua ética, sua forma de organização social, política e econômica, é direito inalienável de todo ser humano. Destaca-se no documento o fato de que todos os artigos abordam questões sensíveis às sociedades ocidentais e dão a elas tratamento segundo a ética moderna produzida por essas sociedades.

Essa observação não pretende desqualificar o documento e questionar sua validade. Pelo contrário, é preciso reconhecer sua importância por afirmar os Direitos Humanos como tema de interesse e jurisdição internacional, impondo limites à ação do Estado moderno quanto ao tratamento dispensado aos seus cidadãos.

Contudo, esse é um reconhecimento que, ao considerar o fato de que os Direitos Humanos são uma construção histórica, ressalta também que os documentos produzidos para enunciar seus princípios expressam uma concepção que fala do seu tempo, na ótica 
do pensamento hegemônico de então. Tal pensamento é expressão de uma localidade com pretensões de se afirmar como universal - o que é algo que causa pouca estranheza em se tratando de formulações europeias, pois, como afirma Santos (1997, p. 112), "todas as culturas tendem a considerar os seus valores máximos como os mais abrangentes, mas apenas a cultura ocidental tende a formulá-los como universais" .

Entendemos que enunciar a necessidade de reconhecimento de Direitos Humanos universais significa anular a pluralidade de sentidos sobre vida, dignidade, composição de família e relação familiar, morte, justiça e liberdade, entre outros, presentes em diferentes localidades. Implica anular as diferenças e ignorar a produção de novos significados possibilitados pelas hibridações culturais que o mundo globalizado intensifica. Além do mais, o alcance do consenso em torno de questões consideradas chave para a convivência no mundo contemporâneo não é apenas uma busca por adesão; faz parte da luta hegemônica travada no plano internacional em um mundo globalizado e multicultural, processo no qual é importante reconhecer que as condições para que diferentes vozes se façam ouvir são extremamente assimétricas.

Essa percepção indica que Direitos Humanos sejam pensados pela afirmação da diferença e não da universalidade, o que fazemos buscando o consenso via diálogo como forma de promoção e valorização desses direitos numa perspectiva que, para distinguir da abordagem dos Direitos Humanos universais, podemos nomear como abordagem agonística, para adotar um termo de Mouffe (2001a) ao formular sua concepção de política democrática.
Ou seja, não se trata do consenso como aquele estado de conciliação com o qual o pensamento moderno funda a ideia de que somos todos iguais e podemos nos entender.

Com Chantal Mouffe (2001a), afirmamos o diálogo conflituoso que institui o consenso conflituoso, provisório e contingente como a própria política, como a própria noção de democracia, abordando a política como discursos e práticas que disputam hegemonia na definição e implementação de novas ordens, ou seja: "Esta questão, a despeito do que pensam os racionalistas, não é como chegar a um consenso racional obtido sem exclusão, o que, com certeza, seria impossível. [...] A novidade da política democrática não é superar esta distinção entre "nós/eles", mas estabelecê-la de uma diferente maneira" (idem, p. 20).

Uma abordagem de Direitos Humanos orientada pela perspectiva agonística atém-se ao diálogo conflituoso. Um diálogo que não quer trazer o outro para uma posição supostamente universal, fixa e homogênea, mas investe em políticas culturais que favoreçam, ampliem os espaços de negociação da diferença e o reconhecimento do caráter sempre contingencial, precário e não literal dos sentidos que produz, em que o deslocamento não linear permite que seja indagada a objetividade sugerida pela racionalidade moderna.

Um diálogo que, ao não buscar a instituição de um único sentido, preserva a possibilidade do sentido ambivalente que cede espaço à diferença. Nesse campo, admite-se a provisoriedade do consenso e da própria hegemonia: consenso conflituoso e hegemonia contingente (Mouffe, 2006), condição para que também a diferença seja admitida e assumida como dimensão constitutiva e, 
portanto, inerradicável do social, e não como algo a ser superado ou eliminado com vistas à realização da igualdade.

A diferente maneira de estabelecer a distinção entre "nós/eles", partindo da democracia agonista (Mouffe, 2001a), não evita o confronto pelo apagamento do "outro" que ameaça - como um inimigo a ser eliminado -, pelo contrário, admite a diferença estimulando o pluralismo agonista por meio de uma relação política na qual o "outro" é o adversário a ser vencido. O foco da questão política migra da luta contra-hegemônica, em que o horizonte é o consenso, para o processo de construção hegemônica, que explicita $\mathrm{e}$ acolhe o antagonismo como elemento constituinte da democracia (Laclau, 2004). Como afirma Mouffe:

Estando consciente do fato de que a diferença é condição de possibilidade para constituir unidade e totalidade ao mesmo tempo que gera seus limites, esta perspectiva agonista pode contribuir para subverter a sempre presente tentação que existe nas sociedades democráticas para tornar suas fronteiras algo "natural" e suas identidades algo "essencial". (idem, p. 22)

Essas são considerações que pretendem problematizar o debate sobre Direitos Humanos, trazendo questões que, embora sejam compreensíveis nas elaborações jurídico-políticas e nos fundamentos de relações internacionais (como o estabelecimento de bases universalistas), não podem ser naturalizadas e adotadas sem crítica pelo campo da educação - naturalização e acriticidade que têm marcado o debate instituinte do currículo de EDsHs.
Propomos que a questão seja situada em outros termos, pois compreendemos que o tratamento de universal a determinado significado implica a aceitação de sua fixidez, qualidade distinta do universal e condição necessária para que significados possam ser enunciados como válidos em todos os tempos e lugares.

Por entendermos que o lugar da fixação da identidade é o mesmo da anulação e da subalternação da diferença, em nome de um sentido supostamente capaz de dar conta de todas as coisas, transitamos no debate sobre Direitos Humanos segundo o enfoque de democracia e política (do político) proposto por Chantal Mouffe, o que sugere o questionamento do modo como a ideia de Direitos Humanos é configurada na modernidade: a dimensão política, orientada pela construção do consenso; e a dimensão cultural, sugestiva de um multiculturalismo conservador e assimilacionista - o mesmo que representa a escola e a EDsHs como espaço de vivência e promoção da igualdade.

Nessa direção, propomos uma abordagem sobre Direitos Humanos que valorize a negociação levada a cabo em diferentes arenas de disputa hegemônica - entre as quais destacamos o currículo escolar -, entendendo que o processo de diálogo exigido para o estabelecimento dos seus elementos configuradores tem um sentido politicamente mais relevante e produtivo do que pretensões de universalidade que supostamente o produto gerado possa obter.

Tal perspectiva se consubstancia na problematização de Direitos Humanos e de escola a partir da emersão da tensão/negociação igualdade/diferença, 
na procura por compreender o que se mantém e o que é recriado quando o mesmo e o outro se encontram para significar educação - mais especificamente, EDsHs.

O enfoque da problemática dos DsHs, valendo-se da sua imersão no contexto mundial contemporâneo - no qual a tensão entre o local e o global coloca em destaque a questão do reconhecimento e direito à diferença se impondo em relação ao discurso da igualdade -, tem conduzido ao questionamento da relevância do campo e levado estudiosos da envergadura de Boaventura Sousa Santos e de Vera Candau a sustentarem a necessidade de reconceitualização ou ressignificação de Direitos Humanos. Em seus estudos recentes, Candau avança das percepções que dicotomizam igualdade e diferença para uma abordagem dos termos como dimensões diferenciadas do social, e não necessariamente polos excludentes, afirmando que: "Não se deve contrapor igualdade e diferença. De fato, a igualdade não está oposta à diferença, e sim à desigualdade, e diferença não se opõe à igualdade e sim à padronização, à produção em série, à uniformidade, a sempre o 'mesmo', à 'mesmice"” (Candau, 2005, p. 18)

Por essa orientação, a questão da diferença situa-se como dimensão cultural, expressando distintos modos de vida, valores e significação, que se constituem e reconstituem no processo dinâmico das relações sociais permeadas por jogos de poder. Em contrapartida, desigualdade corresponde à dimensão sociopolítica das relações sociais, que, nesses jogos de poder, configuram a presença de forças hegemônicas e contra-hegemônicas representadas por grupos sociais em situações assimétricas quanto ao acesso aos bens materiais e simbólicos socialmente produzidos.

Argumentando que a noção de Direitos Humanos configurada pela modernidade se constitui como "uma resposta fraca para questões fortes" (Santos, 2006). E Candau (2008) pondera ser necessário um esforço pela sua ressignificação, proposição que a autora formula com base na noção de igualdade como condição na qual a diferença é reconhecida como legítima e o diferente é tratado como igual, ou seja: passagem da ideia de "igualdade ou diferença" que contrapõe os polos - para a afirmação da "igualdade na diferença" - que os integra e articula - significando "superar toda a desigualdade e, ao mesmo tempo, reconhecer as diferenças culturais" (Candau, 2008, p. 49).

Compreendendo que qualquer pretensão de universalidade é uma ficção criada para subjugar a diferença, sugerimos que a ressignificação proposta pode ser efetiva se o sentido de Direitos Humanos, mais que ampliado e atualizado, puder ser conduzido em outra direção, textualizado com base em referências deslocadas do constructo moderno, o que implica um movimento de cisão em relação às noções de universalidade e igualdade que lhe são constitutiva.

Não se trata apenas de questionar o fato de o universal, ao qual os Direitos Humanos se referem, ser oriundo da concepção eurocêntrica, e sim de afirmar que qualquer pretensão de universalidade é uma ficção criada para subjugar a diferença. Assumir essa radicalidade significa, mais que reconhecer a diferença no sentido de acatar e até valorizar sua existência, compreender 
que a diferença é inerradicável (Mouffe, 2001b) por ser constitutiva do social e do político - do humano, portanto. Sob essa ótica, compreende-se que, ao naturalizar a diferença, o discurso da diversidade a ser respeitada fertiliza as estereotipias que sustentam o discurso colonial (Bhabha, 2005) e camufla a dimensão de poder do processo que a constitui, o que cede espaço tanto para posturas de respeito formal ao outro (assentadas na tolerância) quanto para proposições da sua assimilação ao mesmo como modelo adotado como superior. Assim, concordamos com Barreiros (2009) quando, analisando a questão da diferença no âmbito do debate sobre cultura, afirma que

A noção de diversidade, ao localizar-se no cenário da universalidade, acaba por aceitar a diversidade, assume uma postura que reforça as marcas etnocêntricas e coloniais, cuja base encontra-se no sentido de tolerância. Enquanto a diversidade aloca, reconhece e relativisa conhecimentos culturais pré-dados, a diferença problematiza a divisão binária, que, por ser ambivalente, quebra o reconhecimento e possibilita a negociação. A nosso ver, tratar a diferença dentro da perspectiva da diversidade, como marca da distinção, é uma forma de domesticar a diferença, pois gera uma ilusão de harmonia pluralista para criar consenso. (p. 41)

Desse modo, um ponto de rompimento com as bases explicativas das perspectivas modernas é o descarte do discurso da igualdade, o que se define admitindo a diferença como uma construção discursiva politicamente orien- tada e não como descrição de distinção natural (étnica, geracional, de gênero, de origem regional etc.) ou de escolha individual (religiosa, de opção sexual, política etc.).

No âmbito do debate sobre a ressignificação de Direitos Humanos, consideramos produtivo tecer uma abordagem na qual o eixo seja a diferença e não a proposição da igualdade, como a modernidade consubstancia o campo, porque, mesmo quando descrito como utopia relativa à situação sociopolítica, o termo está carregado de uma redução à acepção moderna e ocidental de organização política e social na qual se pretende que todos e todas estejam igualmente incluídos, o que deixa de fora muitas outras possibilidades, historicamente silenciadas.

Uma visão alternativa de Direitos Humanos que assuma como eixo a diferença pode ser constituída pela ótica da heterogeneidade do social e da democracia pluralista, baseada no entendimento de que o conflito que a diferença produz é constitutivo do social e do político, o que a torna inerradicável. Essa é a perspectiva da democracia radical proposta por Mouffe (2000), que admite uma pluralidade de projetos sociais e de cidadania em posições políticas conflitantes, cujas expressões são concebidas como as de adversários legítimos que compartilham valores e princípios éticos, nos quais o sentido está em disputa (agonismo), e não as de inimigos que devem ser destruídos ou subjugados (antagonismo). Mouffe (2001a) admite que tal relação não prescinde de alguns consensos éticos e políticos, mas lembra que esses são consensos precários, conflituosos, posto serem configurados por processos de significação que expressam interpreta- 
ções conflitantes. Nesse sentido, a autora afirma que, "Emprestando um termo da teoria dos sistemas, nós podemos dizer que a política pluralista pode ser concebida como um "jogo misto", isto é, parte colaborativo e parte conflituoso, e não como um jogo completamente colaborativo, como os liberais o conceberiam” (Mouffe, 2001a, p. 21).

Tal proposição conduz ao entendimento de que o projeto político da "democracia agonística requer criar espaço para o dissenso e criar instituições através das quais este possa se manifestar" (idem, ibidem). Assumindo essa concepção, consideramos pertinente situar o esforço tanto de ressignificação dos Direitos Humanos quanto de busca por uma meta para a escola que corresponda à afirmação do outro como adversário legítimo nos espaços de disputa hegemônica, ideia que rejeita o caráter universalista dos Direitos Humanos por reconhecer no universal um particular hegemonizado - o que o discurso da universalização voltado à promoção da igualdade tenta ocultar.

\section{A questão pedagógica da EDsHs}

Um sentido da escola fundado em uma concepção de Direitos $\mathrm{Hu}$ manos deslocada do paradigma moderno (o que é pressuposto para sua ressignificação) pode ser enunciado pela acepção da escola como arena do dissenso e de articulação de relações contingentes em que os sentidos precários vão sendo instituídos pela negociação da diferença - dinâmica descrita por Laclau e Mouffe (2004) como prática articulatória, pelo que se abdica do discurso da igualdade, da inclusão e do universal.
Esse enfoque abre caminho para que as temáticas da diferença e da contingência da construção identitária ganhem centralidade no debate sobre a escola, âmbito no qual queremos problematizar as questões propriamente pedagógicas relativas à EDsHs.

Nessa direção, apoiamo-nos na referência crítica da interculturalidade que, como propõe Candau, "quer promover uma educação para o reconhecimento do 'outro', para o diálogo entre os diferentes grupos sociais e culturais. Uma educação para a negociação cultural" (2006, p. 234), o que confronta com a perspectiva monocultural que orienta a existência da escola e se constrói como sendo sua função, finalidade e meta. Assim, sem negligenciar a expressiva contribuição das abordagens críticas no campo social e, pelo contrário, partindo delas como arcabouço ético orientador dessas reflexões, procuramos, tanto quanto possível, contribuir para o que consideramos ser um necessário e oportuno deslocamento no foco da escola e dos Direitos Humanos tal qual proposto pela racionalidade moderna.

Nos termos da reflexão que estamos privilegiando, qual seja a proposição do deslocamento da ótica moderna com base no reconhecimento e exercício radical da diferença, indicamos dois elementos articulados que, entendemos, podem atravessar os núcleos de preocupações descritos por Candau (2006) em relação à perspectiva pedagógica intercultural.

O primeiro refere-se ao rompimento com a noção de modelo, princípio que perpassa as elaborações pedagógicas desde Comênius - o professor como o modelo a ser seguido pelos alunos; o processo de construção do conhecimento científico como modelo 
para a constituição das metodologias de ensino; as áreas da ciência como modelo para a organização curricular disciplinarizada da escola; o saber sistematizado como modelo de conhecimento válido, são exemplos de como o fazer pedagógico é configurado pela discursividade hegemônica, o que o torna um campo árido para o trânsito e afirmação da diferença. Ou seja, uma educação intercultural pressupõe que, além do questionamento dos modelos instituídos, a própria ideia de modelo seja desqualificada como razoável para constituir as práticas pedagógicas, ideia pela qual o diálogo intercultural não passa de mais uma estratégia de conformação da diferença.

Desse elemento decorre outro, qual seja, a tendência prescritiva dos discursos voltados à escola, o que se configura fortemente nas abordagens de currículo, de didática e de formação de professores, prescrições que pretendem regular e controlar o que ocorre na escola segundo as determinações dos modelos instituídos, confrontando o discurso da autonomia que frequentemente está presente tanto na abordagem da gestão administrativa e pedagógica da escola como em iniciativas de formação continuada de docentes, sobretudo nas proposições inspiradas nas abordagens críticas, assumem o discurso da identidade do professor como profissional autônomo.

Nos termos pontuados anteriormente, consideramos possível assumir a proposição de processos pedagógicos escolares orientados pela interculturalidade como abordagem compatível com a EDsHs, significada a partir da ideia de democracia radical e consenso conflituoso (Mouffe, 2006).
Em termos dos elementos constitutivos da prática educativa em Direitos Humanos - definição que, como mencionamos, costuma estar presente nos debates na área -, pensamos ser produtiva a análise da questão com base no marco teórico que concebe cultura como construção, como estar sendo, como produto híbrido de enunciação, o que abre espaço para pensar a EDsHs como um dos elementos instituintes da cultura dos Direitos Humanos (e não o inverso - EDsHs como processo socializador da cultura já configurada de Direitos Humanos).

\section{Elementos para a compreensão da produção curricular de EDsHs}

Nossa aproximação ao processo de constituição do currículo escolar de EDsHs direciona-se a dois focos. O primeiro é o processo de produção de documentos curriculares, aspecto no qual abordamos as lutas dos grupos com poder de significar a área - como esses grupos se formam, por que tal condição é dada a esses sujeitos e que premissas informam suas representações sobre currículo.

O segundo foco volta-se à compreensão das marcas inscritas nos textos curriculares produzidos por esses grupos, ressaltando como elementos nucleares dessa aproximação o debate em torno das noções universal, diferença e igualda$d e$ - destacadas como centrais no aporte teórico da nossa abordagem de Direitos Humanos e de escola por serem significantes inscritos no centro das disputas discursivas de ambos os campos, o que ressoa fortemente no processo de constituição do currículo de EDsHs. Nossa 
base empírica de análise são documentos produzidos por sujeitos participantes da comunidade política desse contexto de produção curricular.

Para ajudar a entender as negociações e embates envolvidos no processo de construção dos documentos analisados, e mesmo na própria formação dos grupos relacionados a essa produção, realizamos entrevistas presenciais com pessoas que protagonizaram sua produção coordenando os projetos que lhe deram origem e organizando as práticas para sua consecução.

De forma pontual, os textos analisados foram:

a Documentos relacionados à formulação de diretrizes curriculares voltadas à EDsHs:

Doc. Al: PNEDH - Plano $\mathrm{Na}$ cional de Educação em Direitos Humanos (Brasil, 2007).

Doc. A2: Subsídios para a elaboração das diretrizes gerais da Educação em Direitos Humanos - versão preliminar (Dias; Nader; Silveira, 2007). A3: entrevistas com as organizadoras dos Subsídios para a elaboração das diretrizes gerais da Educação em Direitos Humanos. ${ }^{1}$

b Documentos relacionados a iniciativas de formação continuada de professores/as decorrentes das políticas curriculares voltadas a EDsHs:

\footnotetext{
Apesar de todas as entrevistadas terem autorizado a identificação das falas com os seus nomes, optamos por não proceder desse modo e usar os indicativos Entrevistada A, B e C, em referência aos depoimentos colhidos.
}

Doc. B1: Projeto Capacitação de Educadores da Rede Básica de Ensino em Educação em Direitos Humanos. ${ }^{2}$

Doc. B2: Direitos Humanos: capacitação de educadores - volumes I e II (Zenaide, 2008). B3: entrevistas com as coordenadoras nacionais do Projeto Capacitação de Educadores da Rede Básica de Ensino em Educação em Direitos Humanos (REDH Brasil) e organizadoras da publicação da obra Direitos Humanos: capacitação de educadores - volumes I e II.

Esses dois focos (formulação de diretrizes curriculares e formação de docentes na área) inscrevem-se no conjunto de recomendações do PNEDH (Brasil, 2007) que, quanto à educação básica, já na apresentação do documento, destaca como linha de ação:

- $\quad$ propor diretrizes normativas para a EDsHs;

- promover a formação inicial e continuada dos profissionais, especialmente aqueles da área de educação e de educadores(as) sociais em Direitos Humanos, contemplando as áreas do PNEDH. (p. 19-20)

Disponível em: <www.redhbrasil.net/oprojeto.php>. Acesso em: 18 maio 2010. 


\section{Currículo de EDsHs: sujeitos que significam, sentidos em disputa e marcas discursivas}

Em nossa análise, partimos do questionamento da centralidade do Estado no estabelecimento das políticas curriculares e de como é compreendida a ação do poder por abordagens que percebem a política como elaboração do Estado e a sociedade como campo da sua implementação, quando muito, de contestação e resistência.

Delimitando o papel do Estado na constituição do currículo escolar, consideramos a afirmação de Macedo (2007), que, baseada em Taylor et al., indica que os currículos são formulados não pelo Estado isoladamente, mas por uma comunidade política configurada por burocratas do Estado; acadêmicos; consultores e grupos de interesse, cuja articulação hegemônica é configuradora das estruturas estatais. São essas articulações que produzem e mantêm o discurso das reformas educacionais adotadas por políticas públicas, pelas quais a comunidade política é mobilizada para a definição dos parâmetros a serem adotados por instrumentos normativos que geram critérios de investimento, avaliação, produção de material didático e de formação docente.

A configuração dos grupos que constituem essa comunidade articulada em torno do processo de definição de políticas curriculares de EDsHs é elemento que merece destaque por possibilitar compreender os significados que circulam no campo discursivo da área.

Emergindo das práticas sociais que articulam diferentes sujeitos em torno da afirmação de direitos sociais, a área de EDsHs se constitui muito fortemente com o discurso jurídico-político, mobilizando grupos que focam a questão dos direitos e abordam a educação escolar como via da sustentabilidade e do aprofundamento das conquistas democráticas ou, conforme explicitado no estatuto da REDH, ${ }^{3}$ como "meio para a transformação social".

Situar esse contexto constitutivo da EDsHs ajuda a entender tanto a sua acentuada tendência à divulgação de instrumentos legais (preocupação mais afeita ao campo jurídico-político do que ao propriamente pedagógico), quanto à força do discurso crítico-emancipatório das suas proposições educativas. Além disso, relativiza-se também o fato de a comunidade política que formula as propostas curriculares ser constituída por sujeitos com formação e atividade profissional sem vínculo direto com a educação escolar, sobretudo à escola, seu cotidiano e desafios pedagógicos, o que chamou nossa atenção desde a primeira leitura dos textos. Isso pode ser observado na identificação das pessoas entrevistadas e nos quadros a seguir, ${ }^{4}$ que consideram os/as autores/as dos documentos A1, A2, B1 e B2.

Disponível em: <www.http://www.redhbrasil.net/index.php>. Acesso em: 18 maio 2010.

4 Os quadros foram produzidos para o presente estudo por meio dos dados obtidos na identificação dos autores contida nas publicações analisadas, cruzados com informações do Currículo Lattes e confirmados/ complementados durante as entrevistas. 
1 - Formação acadêmica

\begin{tabular}{|l|c|c|}
\hline \multicolumn{1}{|c|}{ Formação acadêmica } & Número & $\%$ \\
\hline Educação & 7 & 23,34 \\
\hline Direito & 6 & 20,00 \\
\hline História & 7 & 23,34 \\
\hline Psicologia & 2 & 6,66 \\
\hline Filosofia & 4 & 13,34 \\
\hline Sociologia & 2 & 6,66 \\
\hline Não informa & 2 & 6,66 \\
\hline $\begin{array}{l}\text { Obs.: entre os que não possuem formação máxima em } \\
\text { educação, um possui formação anterior na área }\end{array}$ & & \\
\hline
\end{tabular}

2 - Área de atuação

\begin{tabular}{|l|c|c|}
\hline \multicolumn{1}{|c|}{ Área de atuação } & Número & $\%$ \\
\hline Direito (docentes - 5 / discentes - 3) & 8 & 26,68 \\
\hline $\begin{array}{l}\text { Educação escolar/fundamentos teóricos (filosofia da } \\
\text { educação, história da educação, sociologia da educação, } \\
\text { psicologia educacional) }\end{array}$ & 4 & 13,34 \\
\hline História & 4 & 13,34 \\
\hline Filosofia & 3 & 10,00 \\
\hline Ciências sociais (docente - 1 / discente - 1) & 2 & 6,66 \\
\hline $\begin{array}{l}\text { Educação escolar/prática pedagógica (didática, currículo, } \\
\text { prática de ensino, formação de professores, gestão } \\
\text { escolar) }\end{array}$ & 2 & 6,66 \\
\hline Educação popular & 2 & 6,66 \\
\hline $\begin{array}{l}\text { Serviço social } \\
\text { (docente - 1 / discente - 1) }\end{array}$ & 2 & 6,66 \\
\hline Comunicaçãa social & 1 & 3,34 \\
\hline Direito e história & 1 & 3,34 \\
\hline Psicologia & 1 & 3,34 \\
\hline
\end{tabular}

No que tange às entrevistas, descrevendo esse contexto e analisando suas implicações, a Entrevistada C pondera que as iniciativas relativas à definição de normas e diretrizes para a EDsHs têm partido muito fortemente da Secretaria Especial de Direitos Humanos (SEDH), encontrando, da parte do MEC, apoio via Secretaria de
Educação Continuada, Alfabetização e Diversidade (SECAD) que, embora considere importante, não vê como suficiente para assegurar que as escolas assumam as propostas encaminhadas. Exemplificando com o processo de formulação do Plano Nacional de Educação em Direitos Humanos (PNEDH), ela indica que 
[...] a SEDH foi quem "puxou" a discussão pra fazer a interlocução com o MEC. E ao vir pela SEDH, apesar de estarmos no mesmo governo, nós tínhamos de fato dificuldade do MEC assumir isso como política. Hoje já avançou bastante, eles criaram, dentro do MEC, um comitê. Mas, nesse sentido das diretrizes, de uma orientação mais específica, orientação normativa, novamente quem está direcionando é a SEDH. Eu digo sempre o seguinte: se o Plano fosse tomado nas mãos pelo ministro da Educação, como um projeto do MEC, ele já estava em outro patamar. Isso por conta da relação que o MEC tem com todo o sistema, inclusive injetando recursos, para que o Plano pudesse ser uma política. (Entrevistada $\mathrm{C}$ )

Outra questão destacada tanto pela Entrevistada C quanto pela Entrevistada B é o fato de que não é apenas aos gestores públicos que a área da EDsHs deixa de tocar como tema diretamente relacionado à educação; a comunidade acadêmica também parece não estar sensível a ela, como uma questão diretamente relacionada ao campo da educação. Como verificamos a seguir:

Eu não sinto que as entidades da educação estejam preocupadas com isso. Eu não percebo essa discussão passando pela ANPEd [Associação Nacional de Pós-Graduação e Pesquisa em Educação], pela ANFOPE [Associação Nacional pela Formação de Profissionais da Educação] e muito menos pela ANPAE [Associação Nacional de Política e Admi- nistração da Educação]... Era uma temática para se trazer à tona. (Entrevistada C)

A Entrevistada B reforça essa percepção ao afirmar que

A educação ainda é muito resistente ao tema dos Direitos Humanos. O pessoal trabalha temas dos Direitos Humanos como diversidade, mas não admite que é Direitos Humanos. Há um preconceito no Brasil de que Direitos Humanos é defesa de bandido... Direitos Humanos ainda causa estranhamento nas pessoas.

Ao analisarmos os documentos destacados pelo estudo - relativos a currículo escolar e à formação continuada de professores, temáticas tão específicas da escola -, é importante situar esse perfil dos/as autores/as no contexto de construção discursiva da área da EDsHs, do qual emergem as iniciativas na área, o que ajuda a compreender os significados que circulam, a abordagem que se destaca e as enunciações que prevalecem nos textos.

\section{Ação pedagógica: sentidos em disputa}

A pouca inserção de profissionais da educação no grupo estudado corresponde ao que depreendemos como o sentido que atravessa o conteúdo do material analisado, no qual percebemos que, mesmo ao trazer a temática dos Direitos Humanos para o campo da educação, o que prevalece é uma maior proximidade à perspectiva jurídico-política, seja difundindo os instrumentos legais, seja investindo na 
conscientização quanto às formas de fazer valer os direitos existentes.

É muito forte a ideia de que a EDsHs se dirige à difusão dos mecanismos de proteção e à exigência do cumprimento das leis como expressão de exercício de cidadania, percepção que sobressai mesmo diante da consideração de que a área necessita ser pensada-pelas questões pedagógicas, mais do que pelas demandas do campo jurídico, como se configura hoje. Isso pode ser apreendido pela fala da Entrevistada B quando, referindo-se aos autores do material pedagógico relativo ao curso de capacitação de educadores (Doc. B2), expressa uma preocupação relativa ao que identifica como a necessidade de maior implicação da educação na abordagem da EDsHs.

Ninguém chega na dimensão educativa e pedagógica. Só poucos, acho que uma Vera Candau, uma Aida [Monteiro]... A maioria trabalha Direito Internacional e Direitos Humanos, a história dos Direitos Humanos e os mecanismos de proteção e para por aí... [...] A gente diz para eles: "para ser Educação em Direitos Humanos nós temos que trabalhar várias dimensões [...]. Tem a convenção contra o racismo, tem a convenção do México sobre Educação em Direitos Humanos, tem a convenção dos direitos da criança, tem a convenção sobre a discriminação no ensino... Vocês têm que buscar naquele corpo de conquistas jurídicas o que tem diálogo com a educação..." O professor que está na rede básica de ensino precisa conhecer o Estatuto da Criança, ele precisa conhecer a Lei Maria da Penha, ele precisa conhecer a convenção que fala sobre a discriminação racial no ensino, ele precisa conhecer aquilo que rebate no processo de formação do aluno. $\mathrm{O}$ pessoal do Direito só fala nas coisas gerais.

Não percebemos no tom ou no próprio conteúdo das observações das entrevistadas uma crítica à postura assumida pelo pessoal do Direito (termo adotado na condição coloquial do depoimento oral aqui transcrito), mas uma percepção de que há pouca inserção do campo educativo no debate da área da EDsHs e de que isso poderia ser corrigido com maior envolvimento no processo de construção curricular, por parte das instâncias do poder estatal responsáveis pela elaboração de políticas em educação.

Contudo, analisando esta última fala, vemos que, ao assumir uma postura crítica quanto à excessiva ancoragem da EDsHs no campo jurídico, o que se explicita é uma abordagem que também não avança muito no manejo de questões relativas à exigibilidade do cumprimento da legislação. A diferença é que reclama uma seleção de instrumentos legais com temas menos gerais e que tenham relação mais explícita ou imediata com o universo de preocupações da escola ou com as questões com as quais educadores/as se defrontam no cotidiano escolar, como direitos da criança, direitos da mulher, manifestações de preconceitos étnico-raciais, religiosos, entre outros, o que se torna um referendo para a preponderância da dimensão jurídico-política sobre a pedagógica na construção do currículo de EDsHs.

A dimensão universal, na totalidade formada pelos diferentes sujeitos que integram o grupo analisado, é 
configurada pela inserção, comum na concepção de escola como espaço de socialização, de uma determinada cultura com vistas à formação para a cidadania e à construção da igualdade - o que identificamos como função, finalidade e meta da escola moderna. Tal percepção atravessa todos os textos e pode ser apreendida, por exemplo, nos trechos a seguir:

A educação básica visa oferecer condições de acesso à cidadania mediante práticas educativas de sistematização dos conhecimentos socialmente acumulados pela humanidade. Tais práticas são formalizadas no âmbito da escola, cuja função primordial é a construção de conhecimentos gerais que permitam aos educandos se apropriar dos bens culturais historicamente produzidos pela sociedade. (Doc. A2, Dias; Nader; Silveira, 2007, p. 22)

A gente entende que a escola não é o único local, mas é um lugar privilegiado pra que a gente possa trabalhar na perspectiva de socialização da cultura da educação em direito humanos. (Entrevistada A)

Com base nessa construção comum relativa à escola, abordagens diferenciadas quanto ao sentido da ação pedagógica da EDsHs podem ser identificadas, tentativas de preenchimento dos sentidos que deslizam na fronteira dos discursos jurídicos e do propriamente pedagógico.

\section{Abordagem jurídica}

A abordagem jurídica é uma abordagem informada pela proposição de ampliar a exigibilidade quanto ao cumprimento dos direitos individuais e coletivos consagrados pelos Direitos Humanos. Destaca-se a ideia de processos educativos voltados à difusão de instrumentos de reconhecimento de direitos (leis, decretos, acordos, convenções); conscientização, sensibilização e mobilização relativas à assunção de posturas de defesa e proteção desses direitos; e socialização dos valores que fundamentam o campo dos Direitos Humanos - arcabouço jurídico, político e ético afirmado como constitutivos da cultura dos Direitos Humanos.

A força da perspectiva jurídica na constituição do currículo de EDsHs pode ser percebida menos pela explicitação do caráter informativo que a constitui do que pelos sinais e ausências que chamam nossa atenção quando examinamos os documentos.

Do Doc. B1 ressaltamos dois aspectos que sinalizam nessa direção. $\mathrm{O}$ primeiro se destaca pela análise das instâncias da universidade que respondem pela concepção do projeto e pela sua coordenação e implementação. É um projeto coordenado pela Pró-reitoria de Extensão e Assuntos Comunitários da UFPB e pelo Núcleo de Cidadania e Direitos Humanos. Esse Núcleo, vinculado ao gabinete do reitor e ao conselho universitário, é voltado ao desenvolvimento de atividades de ensino, pesquisa e extensão na área dos Direitos Humanos. Tem caráter interdisciplinar e é constituído por professores de diferentes áreas da instituição. Em 2004, ${ }^{5}$ o núcleo tinha 18 membros vinculados

Não localizamos atualização recente relativa à composição do núcleo no endereço http://www.cchla.ufpb.br/ncdh. Acesso em: 13 maio 2010 . 
aos seguintes departamentos: seis do departamento de ciências jurídicas, três do serviço social, dois da história, dois da sociologia, dois da filosofia, dois da psicologia e um da antropologia.

$\mathrm{O}$ segundo aspecto diz respeito à referência teórica do projeto: entre os 102 títulos relacionados na bibliografia, cinquenta tratam de temas focados na área de direito; trinta, de educação; e 32 de outras áreas, como filosofia e política. Esses sinais são expressão da força do polo jurídico do termo (Direitos Humanos) em relação ao polo pedagógico (educação) na concepção do projeto, o que é reforçado pela ausência do departamento de educação da universidade em um projeto institucional que foca a educação básica e se volta para a formação de professores.

No material pedagógico do curso (Doc. B2), essa questão acentua-se, ao observamos os temas e a distribuição da carga horária relativa ao curso de formação de professores: apenas 15 das 60 horas presenciais são destinadas ao debate de questões focadas na educação escolar.

A análise do conteúdo dos documentos não desfaz essa impressão de prevalência do campo do direito sobre o da educação no processo de constituição do currículo de EDsHs. Com exceção de alguns textos, notadamente os do Módulo IV, mas não todos, a falta de base de argumentação pedagógica ou de preocupação por articular os temas tratados à problemática escolar é uma ausência que fala do que está presente no campo de disputa discursiva na área, tanto quanto revela a recorrência de descrições, listagens e comentários sobre leis, decretos, acordos internacionais, convenções etc. relacionadas à conquista de direitos ao longo da história da humanidade.

\section{Abordagem pedagógica}

A abordagem pedagógica quanto ao sentido da EDsHs é compreendida como algo que extrapola o sentido marcadamente informativo delimitado pela perspectiva jurídica para enfatizar sua dimensão formativa - no caso, a formação de sujeitos de direitos com potencial de ação transformadora na sociedade.

Marcadamente influenciada pela obra de Paulo Freire, essa perspectiva parte de fragmentos amplamente difundidos e reiterados pelo discurso crítico: democracia, cidadania, autonomia, transformação social, participação, questões que aparecem enfocadas de muitas formas, como se pode exemplificar com o trecho a seguir:

A Educação em/para os Direitos Humanos deve transversalizar todo o currículo escolar, de modo a oferecer aos educandos um arcabouço teórico-metodológico que norteie práticas de tolerância, de respeito à diversidade e ao bem comum, de solidariedade e de paz, realçando os valores necessários à dignidade humana. Para tanto, faz-se necessário que as escolas possam agregar aos seus projetos pedagógicos não apenas conteúdos, mas, fundamentalmente, experiências e práticas que ajudem a fomentar/fortalecer atitudes, condutas, valores e comportamentos orientados para o respeito, a cultura e a educação em/ para os Direitos Humanos. (Doc. B2, Zenaide, 2008, p. 159)

Aparece aqui um importante e consolidado elemento na construção do sentido de EDsHs presente nos documentos, o que se expressa pela afirmação da EDsHs como estratégia 
de difusão da cultura de Direitos Humanos, compreendida como arcabouço jurídico, parâmetro ético e projeto político de validade universal. Situando a escola como instituição cuja função é a socialização da cultura expropriada das classes subalternas pelas classes dominantes, a EDsHs é representada como instrumento de transformação social, consolidação da democracia e promoção da cidadania.

Socializar em Direitos Humanos implica implantar processos educativos que possam difundir, se não para absolutamente todos (esse é o horizonte desejável), mas para o maior número possível de pessoas, concepções e práticas culturais para que elas se percebam e se formem como sujeitos detentores de direitos porque sujeitos de dignidade. Isso significa que as pessoas, mediante processos educativos assim direcionados, tomem consciência da sua natureza humana e que lhes sejam possibilitadas condições para lutarem e exigirem a realização do seu ser humano. Em síntese, que tais processos visem tornar humanos os seres humanos. (Doc. A2, Dias; Nader; Silveira, 2007, p. 5)

Percebemos que, operando com a lógica de Direitos Humanos como uma cultura dada (a cultura dos Direitos Humanos), vai sendo forjado um discurso pedagógico que não escapa da marca diretiva que prescreve aonde se deve chegar e investe na normatização como elemento fundamental para alcançar o ponto pré-almejado. Ou seja, uma forte presença do discurso crítico na significação e afirmação de autonomia que, quando se aproxima da escola, contraditoriamente, o faz prescrevendo e normatizando o que nela deve ser feito, o que nela deve ser tratado. A ambiguidade da convivência entre participação e normatização, autonomia e prescrição é uma marca que atravessa todo o material analisado e resulta em abordagem pedagógica respaldada por acepções prescritivas, normativas e instrumentais.

\section{Marcas discursivas dos textos curriculares: universal/particular e igualdade/diferença}

A noção de direitos como construção histórica e social é o princípio pelo qual os Direitos Humanos são abordados como cultura universal; com essa condição tem-se sustentado a validade e a importância da sua socialização via processos escolares. Na maioria dos textos curriculares analisados, tal universalidade é tratada como um dado que não necessita ser problematizadoé uma verdade da qual se parte, um princípio sem o qual Direitos Humanos seriam impensáveis.

Ao rejeitar a pretensão universalizante, característica da construção da ideia de Direitos Humanos, não desconsideramos a importância da mobilização pelo diálogo e busca de formas não violentas de relação com a diferença (que tem movido grupos que se articulam pela promoção e defesa do que é significado como Direitos Humanos na contemporaneidade ocidental). Contudo, queremos deslocar o eixo em torno do qual o debate vem sendo desenvolvido, por considerar que se encontra esgotada sua capacidade de oferecer compreensões alternativas à questão da relação universal/particular, 
dada a circularidade da argumentação que, com diferentes enfoques, se empenha em afirmar o caráter supracultural dos princípios enunciados pelos Direitos Humanos, ora sustentando a existência de uma essência capaz de conter toda diferença - o que resulta na afirmação de uma universalidade multicultural-, ora buscando compatibilizar ou superar o dilema entre universalismo e particularismo - o que parte do princípio da incompatibilidade entre ambos.

Optamos por trabalhar a questão apoiando-nos no modo como Laclau e Mouffe (2004) abordam a constituição do social, qual seja, as disputas entre diferentes particulares resultam na hegemonia daquele que, em determinado momento, é capaz de apresentar seus objetivos como relativos às demandas de outros grupos, o que possibilita que seus conteúdos sejam divulgados como universais. Assim, o universal é um particular que em determinado momento alcança a condição de universal por adquirir a capacidade de articular em torno de si outros discursos, tornando-se hegemônico. Mas isso não suprime os particulares representados provisoriamente por ele. Esta é a relação política: uma relação na qual os particulares estão permanentemente em disputa hegemônica pela condição de representar o todo.

Nessa perspectiva, rompe-se com o entendimento de universal e particular como polos opostos, excludentes, para admitir que universal e particular são dimensões em disputa, aspectos constitutivos do social, posto que são elementos inerentes à relação política. Então, já não se trata de estabelecer se existe ou não um universal, mas de procurar entender em que condições os discursos particulares disputam hegemonia - ou buscam universalizar-se.
Ao abordar essas questões pelos documentos analisados, percebemos que é nas diferentes apreensões do termo "cultura" que se torna possível perceber ambiguidades que permeiam o campo e o modo como se constitui sua acepção universalista, cuja hegemonia pensamos ser importante questionar.

As passagens a seguir, extraídas dos Docs. A1 e A2, exemplificam a relevância do fragmento "cultura" na construção discursiva da área e trazem elementos importantes quanto às significações que circulam, negociam e se hibridizam nesse processo: "A educação deve ter a função de desenvolver uma cultura de Direitos Humanos em todos os espaços sociais" (Doc. A1, Brasil, 2007, p. 23). E ainda temos: "Todo processo educativo é processo socializador de uma coletividade humana, de um grupo social, de um indivíduo, em uma determinada cultura. Portanto, a EDsHs é um processo de socialização em uma cultura de Direitos Humanos" (Doc. A2, Dias; Nader; Silveira, 2007, p. 5).

Observamos que a significação assumida para o termo desliza na fronteira entre acepções de cultura como repertório, patrimônio, arcabouço de saberes que cabe à escola socializar - o que propõe a ideia de cultura como objeto de ensino (Macedo, 2004) - e significações de cultura que incorporam elementos de abordagens discursivas, permitindo que cultura seja admitida como enunciação, como produção partilhada na prática social, devendo a escola, segundo o entendimento expresso nos textos em questão, desenvolver a conscientização, disponibilizar os instrumentos de reflexão crítica e viabilizar situações que favoreçam tal produção. 
É oportuno ressaltar que essa construção, ao mesmo tempo em que afirma que cultura não é um elemento fixo a ser socializado e que sua produção não é privilégio de grupos específicos, condiciona sua consecução ao domínio de determinados conhecimentos e habilidades identificados com determinados grupos, o que os coloca em um patamar diferenciado em relação aos demais. $\mathrm{O}$ trecho a seguir pontua bem o modo como determinadas concepções se apresentam como moldura para o que pode ser admitido como válido, digno ou civilizado.

Felizmente, na contraface da trajetória histórica, a humanidade vem construindo caminhos visando à participação política com autonomia, através de experiências que se consolidaram em um princípio indispensável aos Direitos Humanos: a democracia. Somente sociedades democráticas, em que a todas as pessoas seja garantido o estatuto multidimensional de cidadão, possibilitarão a sua dignidade como ser humano. A democracia precisa, pois, ser assumida como valor permanente e dotada de uma qualidade ética que oportunize condições simétricas de participação. A ética democrática pressupõe igualdade, liberdade e solidariedade. Pressupõe conceber os cidadãos como sujeitos de direitos. (Doc. A2, Dias; Nader; Silveira, 2007, p. 10)

Afirma-se, com isso, que fora da lógica moderna - na qual a democracia foi pensada - não existem Direitos Humanos, ou, em outras palavras, uma produção local da discursividade do ocidente europeu é condição para a existência de algo cuja universalidade é ponto de referência basilar e inegociável. No corpo dos documentos analisados, esse princípio não é objeto de questionamento. Nos diferentes textos, uns problematizam para em seguida sustentar, outros remetem à universalidade dos Direitos Humanos como um dado, todos referendando a ideia de que os parâmetros éticos e o projeto político dos Direitos Humanos são condições de humanidade posicionada acima das diferenças culturais, como se pode depreender da passagem a seguir, extraída do documento de capacitação dos docentes (Doc. B1), explicitando os fundamentos histórico-filosóficos dos Direitos Humanos.

Direitos Humanos guardam relação com valores e interesses que julgamos ser fundamentais e que não podem ser barganhados por outros valores ou interesses secundários [...]. Não ser universal não significa que não deveriam ser universalizados de forma democrática e respeitosa da diversidade cultural. (Doc. B1, p. 17-18)

Sem desconsiderar a relevância das abordagens críticas no âmbito das formulações modernas, cuja contribuição traz a ideia de direitos do campo individual para o social e coletivo ampliando o espectro e aprofundando o alcance do que se entende por Direitos Humanos -, é produtivo reconhecer o seu limite para explicar questões como a da convivência multicultural, que emergem com força perante a intensificação do fenômeno da globalização e sugerem uma abordagem que considere a complexidade da constituição do social para além dos binarismos explora- 
do/explorador; dominante/dominado, selvagem/civilizado.

A ressignificação dos Direitos Humanos passa pelo deslocamento da ideia de que no confronto entre esses polos (e na exclusão de um deles) se situa o campo da promoção e defesa de direitos universais abordados como expressão de um horizonte de igualdade e justiça, objetividade a ser alcançada pelas lutas sociais, em que se destaca a mediação de uma educação centrada na conscientização, no desenvolvimento da criticidade e da resistência. E é no âmbito do debate sobre questões relativas à cultura que a consolidada expressão do pensamento crítico na constituição da ideia de escola, de Direitos Humanos e de EDsHs encontra um embate que, não sendo pura resistência, se abre à possibilidade de enunciação.

Outra questão, a essa intimamente relacionada, que se destaca com força nesse debate é relativa à igualdade/diferença. Nos documentos que analisamos, vemos que esse é um fio condutor da argumentação relativa à afirmação dos Direitos Humanos e dos fundamentos e proposições relativas a processos educativos na área. Apesar disso, chama a atenção o fato de essas questões serem abordadas sem uma problematização que busque situá-las no âmbito do debate que tem gerado tantos questionamentos relativos às acepções dos termos.

A temática encontra destaque já na introdução do Doc. A2, quando é proposta a contextualização da EDsHs a partir dos "inúmeros processos sócio-históricos da contemporaneidade" (Dias; Nader; Silveira, 2007, p. 3), cujos elementos configuradores são descritos como diretamente relacionados a maior visibilidade, expressividade e centrali- dade da questão da diferença-cultural, de gênero, de orientação sexual, étnico-racial, geracional, civilizatória - referida a contextos de disputa política na qual a diferença é admitida como o outro excluído - que negros, índios, mulheres, jovens etc. corporificam - , estruturando uma totalidade a base de identidades determinadas por uma origem comum dada pela cor da pele, idade, gênero etc.

Nesses termos, diferença é tomada como diversidade, pluralidade, multiplicidade cultural e demanda o reconhecimento da heterogeneidade como legítima, o que implica afirmação do discurso da tolerância, convivência pacífica com o outro e a busca do consenso como estruturante da noção de Direitos Humanos, sem que se indague sobre a permanência da ideia de um mesmo como modelo (de saber, de ética, de organização social, política e econômica etc.) a ser alcançado por todos. Pelo contrário, essa é uma possibilidade apresentada como condição de alcance de uma almejada igualdade. Ou seja, no tratamento da diferença como diversidade, o discurso articulado converge para uma perspectiva condescendente, que admite a inclusão do outro sem, contudo, questionar a ordem na qual esse outro foi construído como tal, o que entendemos como uma condição para a imputação de valor universal aos princípios enunciados pelos Direitos Humanos.

Essa é a perspectiva que predomina nos documentos relativamente à significação da diferença. Na leitura desses textos, consideramos importante sinalizar a ausência de um questionamento relativo à dimensão de poder presente na constituição dos direitos e deveres consagrados pelas instituições sociais, nas quais se advoga que todos e todas devem 
ser incluídos/as. Sem isso, a liberdade de manifestação das diversidades e o direito ao pensamento divergente que o discurso crítico proclama representam um avanço formal (embora devamos reconhecer que politicamente importante) em relação às afirmações modernas definidas pelas abordagens liberais. Do ponto de vista da diferença, pensamos ser pertinente não camuflar que todo tipo de codificação (mesmo as normativo-legais) representa a hegemonia de um particular constituído como universal em um processo de disputa política.

Assim, a percepção de democracia baseada na busca do consenso e da igualdade com respeito à pluralidade cultural, ideia que perpassa o conjunto dos documentos analisados, contradiz os princípios que enuncia, justamente por evitar a permanente negociação da diferença que a afirmação da igualdade interdita.

Reiteramos, então, a opção pela leitura da questão tal qual propõem Laclau e Mouffe (2004), para os quais a democracia é entendida como experiência permanente de estabelecimento de relação com a diferença, vivência na qual o poder está sempre presente como elemento crucial da política. Tal visão desloca sensivelmente o sentido de democracia configurado pelo pensamento moderno no qual o conflito é algo a ser superado.

Admitindo a inerradicabilidade do conflito, aceitamos a inerradicabilidade da diferença (a diferença que não aparece é, na verdade, silenciada) e, paradoxalmente, afirmamos a democracia como processo político plural e sempre inconcluso.

Em outras palavras, imaginar a celebração de um consenso final em torno de um determinado projeto social (consenso pelo qual diferentes forças parecem se mover) seria o mesmo que supor (e desejar) uma situação de inexistência de conflito e, com isso, o fim da própria política e da democracia.

Essa percepção possibilita que se ressitue a própria ideia de Direitos Humanos, abrindo espaço para construções menos idealistas e mais conectadas com as questões da contemporaneidade, marcadas pelos dilemas e tensões advindos de sociedades multiculturais, permitindo que a tensão igualdade/ diferença seja problematizada em termos distintos dos afirmados pela modernidade.

\section{EDsHs - tradição e performance}

Nos textos analisados, a ausência de problematização das questões relativas a Direitos Humanos no âmbito da emergência das tensões contemporâneas resulta na afirmação de significados unívocos e totalizantes, deixando de fora importantes questões que têm alimentado e tensionado o debate na área, como o questionamento da afirmação inequívoca do caráter universal dos Direitos Humanos, o embate entre diferença e diversidade e as múltiplas abordagens sobre identidade e construção identitária e sobre cultura e multiculturalismo.

Vemos, por exemplo, que, embora muitas passagens dos textos se refiram a processos de produção cultural, o sentido que prevalece é o de cultura como repertório fixo - possivelmente reconstruído para fazer frente a novas exigências -, mas arcabouço de saberes instituídos que se socializam pela ação escolar. A relação com os saberes outros, postos como cultura de origem dos alunos, indica sua consideração 
como ponto de partida para chegar a um patamar mais elaborado de conhecimento e de cultura que necessita da escola para ser apropriada.

Indica também a apreensão da incompletude do saber hegemônico e a necessidade de diálogo com outras construções, condição de realização da própria identidade, pois, como pontua Stuart Hall, "as identidades são construídas por meio da diferença, e não fora dela" (Hall, 2003, p. 45), o que permite que o currículo seja tratado não só como expressão da tradição, mas também, de forma ambivalente, como possibilidade de performance.

Tal abordagem converge para a ideia de EDsHs como processo socializador na cultura dos Direitos Humanos, descrito como difusão de "postura compreensiva das diversidades socioculturais [proporcionando] uma aprendizagem da convivência e da tolerância" (Doc. A2, Dias; Nader; Silveira, 2007, p. 17).

Desse entendimento deriva uma noção orientada à divulgação de um determinado modelo - no caso, os explicitados pelos princípios ético-políticos da cultura dos Direitos Humanos - com vistas à assunção de posturas, valores e compromissos definidos como compatíveis com essa cultura e expressos nos seus instrumentos de sistematização. Nessa direção caminha a acepção pedagógica construída nos documentos analisados, nos quais o discurso pedagógico assume a discursividade do campo jurídico; valendo-se dele cria modelos e nele se apoia para prescrever, em que a força do campo jurídico, desde a constituição dos grupos com poder de significar Direitos Humanos e EDsHs, passando pelos temas abordados e pelas instâncias institucionais envolvidas, indica a determinação prévia de um conteúdo curricular a ser desenvolvido pela escola em uma prática prescritiva aceita como inexorável pelo campo pedagógico.

Pensando na efetivação de uma educação intercultural nos termos propostos por Candau (2008) - que com ela assumimos como uma perspectiva pedagógica que se encontra em processo ainda inicial de construção -, entendemos que o questionamento da ideia de modelo e o enfrentamento das práticas prescritivas são pressupostos para um repensar a escola conjugado com uma ressignificação de Direitos Humanos. Parece-nos que, por um lado, a ideia de prescrição anula a proclamada autonomia exigida pelo próprio discurso dos Direitos Humanos, pois não existe autonomia se todas as decisões já foram tomadas; e, por outro, a ideia de diálogo (e, em decorrência, o espaço da diferença) enfrenta o obstáculo da existência de um modelo que determina de antemão a que resultado esse diálogo precisa chegar.

Nesse movimento, que envolve continuidades e rupturas, o campo analisado configura uma arena de disputa hegemônica pela significação de Direitos Humanos e constituição do currículo de EDsHs, na qual sentidos que não transitam no campo discursivo da modernidade (sentidos produzidos pela diferença) têm pouca expressão ou mesmo possibilidade de inserção.

$\mathrm{O}$ respeito à diferença, abordada como diversidade, pluralidade, mosaico cultural, múltiplas identidades originais com direito a ter sua dignidade reconhecida por expressarem a riqueza do humano, conduz à proposição de práticas de convivência baseadas na aceitação e na tolerância, o que pode 
ser feito sem que se questione como pressuposto político a forte hegemonia do discurso moderno, marcado pelo ímpeto colonialista de universalização dos princípios que enuncia, condição de afirmação do discurso de Direitos Humanos produzido pela modernidade que, nesses termos, é incompatível com os interesses da diferença e da democracia.

Pensando em uma abordagem de Direitos Humanos ressignificada por uma ideia de diferença como produto discursivo, e de currículo como uma das práticas sociais de produção cultural, de enunciação, podemos compreender Direitos Humanos como algo que resulta também dessas práticas. Pensar a escola não como espaço no qual a cultura dos DsHs se socializa, mas espaço no qual essa cultura é produzida e, portanto, arena de produção do currículo de EDsHs.

É nesse entre-lugar, no espaço entre o nós e os outros, aquele que não é nem nosso nem dos outros, que podemos pensar num currículo como produção cultural, espaço híbrido e dialógico, gerador de identidades fluidas, por onde as culturas deslizam, se reconhecem e valorizam suas diferenças ao mesmo tempo em que as repudiam, num discurso ambivalente. (Barreiros, 2009, p. 65)

Essa é uma possibilidade alternativa para que os Direitos Humanos possam ser abordados não como um conjunto normativo a ser difundido, defendido e seguido, e sim como uma experiência a ser construída, uma ética a ser inventada no diálogo que incorpora a diferença, admite o conflito e enfatiza a dimensão política que impregna toda relação social e institui sentidos provisórios e contingentes nos permanentes processos de disputa hegemônica.

\section{Referências bibliográficas}

BARREIROS, Débora. Todos iguais... todos diferentes.Problematizando os discursos que constituem a prática curricular. 2009. 241f. Tese (Doutorado em Educação) - Faculdade de Educação, Universidade do Estado do Rio de Janeiro, Rio de Janeiro, 2009.

BHABHA, Homi. O local da cultura. Belo Horizonte: Editora UFMG, 2005.

BRASIL. Comitê Nacional de Educação em Direitos Humanos. Plano Nacional de Educação em Direitos Humanos. Brasília: Secretaria Especial dos Direitos Humanos/Ministério de Educação/Ministério de Justiça/UNESCO, 2007.

CANDAU, Vera M. Direitos Humanos, educação e interculturalidade: as tensões entre igualdade e diferença. Revista Brasileira de Educação, v. 13, n. 37, p. 45-56, jan./abr. 2008.

Educação em Direitos Humanos: políticas curriculares. In: LOPES, Alice; MAGEDO, Elizabeth (Orgs.). Políticas de currículo em múltiplos contextos. São Paulo: Cortez, 2006.

Sociedade multicultural e educação: tensões e desafios. In: CANDAU, Vera (Org.). Culturas e educação: entre o crítico e o pós-crítico. Rio de Janeiro: DP\&A, 2005.

DIAS, Adelaide Alves; NADER, Alexandre Antonio Gili; SILVEIRA, Rosa Maria Godoy (Orgs.). Subsídios para a elaboração das diretrizes gerais da educação em Direitos Humanos: versão preliminar. João Pessoa: Editora Universitária/UFPB, 2007.

HALL, Stuart. Da diáspora: identidades e mediações culturais. Belo Horizonte: Editora UFMG/Brasília: UNESCO, 2003.

LACLAU, Ernesto; MOUFFE, C. Hegemonia y estratégia socialista. Buenos Aires: Fondo de Gultura Económica, 2004. 
MACEDO, Elizabeth F. Currículo, cultura e diferença. O caso da multieducação com ênfase nas ciências. Projeto de Pesquisa apresentado ao CNPq. 2007. Disponível em: <www.currículo-uerj.pro.br>. Acesso em: 2 ago. 2010.

Currículo e hibridismo: para po-

litizar o currículo como cultura. Educação em Foco, n. 8, p. 13-30. 2004.

MOUFFE, Chantal. La paradoja democrática. Barcelona: Gedisa, 2000.

Globalização e cidadania democrática. Revista da Faculdade de Direito da UFPR, Paraná, v. 36, p. 17-25, 2001a. Disponível em: <http://ojs.c3sl. ufpr.br/ojs2/index.php/direito/article/ view/1779/1476 > . Acesso em: 26 fev. 2011.

Identidade democrática e política pluralista. In: MENDES, Cândido (Org.). Pluralismo cultural, identidade e globalização. Rio de Janeiro: Record, 2001b.

Por um modelo agonístico de democracia. 2006. Disponível em: <http://bvc.cgu.gov.br/bitstream/123456789/1440/1/31108.pdf>. Acesso em: 26 jan. 2008.

PIOVESAN, Flávia. Concepção contemporânea de Direitos Humanos. In: HADDAD, S.; GERACIANO, M. (Orgs.). A educação entre os Direitos Humanos. São Paulo: Cortez e Associados/Ação Educativa, 2006.

SANTOS, Boaventura de S. Uma concepção multicultural de Direitos Humanos. Revista de Cultura e Política, São Paulo: Lua Nova, n. 48, p. 11-32. 1997.

SANTOS, Sônia Regina Mendes. A formação de professores pesquisadores nos centros de pesquisa e desenvolvimento da educação: um exercício de reflexão crítica. In: REUNIÃO ANUAL DA ANPEd, 29., 2006, Caxambu. Anais... Caxambu.

ZENAIDE, Maria Nazaré Tavares et al. Direitos Humanos: capacitação de educadores.
João Pessoa: Editora Universitária/UFPB, 2008, v. I e II.

AURA HELENA RAMOS doutorou-se em educação pelo Programa de Pós-Graduação em Educação (ProPEd/ UERJ), na Universidade do Estado do Rio de Janeiro, defendendo tese na qual analisa o processo de constituição do currículo de EDsHs no Brasil. Durante dez anos atuou como docente na rede pública de ensino fundamental e médio do Rio de Janeiro. É professora adjunta da UERJ/Faculdade de Educação da Baixada Fluminense (FEBF). Na FEBF, é integrante do Programa de Pós-Graduação em Educação, Cultura e Comunicação em Periferias Urbanas, membro do Grupo de Pesquisa "Currículo, Formação e EDsHs" e coordena, desde 1999, o eixo de Direitos Humanos do Núcleo de Educação Continuada (NEC) de professores, atividade de extensão acadêmica que desenvolve projetos de investigação e intervenção pedagógica nas áreas de EDsHs e educação ambiental. Publicações recentes: em coautoria com FERREIRA, Elisabete. Gestão escolar, protagonismo docente e formação continuada de professores (In: TURA, M. de Lourdes Rangel; LEITE, Carlinda (Orgs.). Questões de currículo e trabalho docente. Rio de Janeiro: Quartet, p. 315-336. 2010); e O lugar da diferença no currículo de educação em Direitos Humanos. Rio de Janeiro: Quartet, 2011 (no prelo). E-mail: aura@uerj.br

Recebido em outubro de 2010 Aprovado em outubro de 2010 


\section{Educação em Direitos Humanos: local da diferença}

O estudo investiga a constituição do currículo de Educação em Direitos Humanos no Brasil, procurando identificar os sujeitos com poder de significar a área e os sentidos em disputa nesse processo - destacadamente o modo como a diferença se articula e constrói consensos nesses espaços curriculares. Focaliza textos voltados à formação continuada de educadores e à formulação de diretrizes curriculares de Educação em Direitos Humanos, produzidos em função de projeto implementado com apoio do Ministério da Educação. Argumenta favoravelmente à assunção de uma noção de Direitos Humanos como espaço de 
expressão da diferença, arena de dissenso, a partir do que se questionam as práticas prescritivas afirmativas de modelos universalizados que caracterizam políticas curriculares, perspectiva que pode ser identificada na experiência analisada de constituição do currículo de Educação em Direitos Humanos.

Palavras-chave: Educação em Direitos Humanos; Direitos Humanos; política curricular; diferença.

\section{Education in Human Rights: place of the difference}

This research investigates the structure of the curriculum of Education in Human Rights in Brazil, seeking to identify the subjects with power to signify the area and the meanings in dispute in that process - particularly how the difference is articulated and constructs consensuses in those curricular spaces. The focus was on texts about the continued training of educators and the formulation of curricular guidelines for education in human rights produced due to a nation-wide project supported by the Ministry of Education. It argues in favor of assuming a notion of Human Rights as a space for expressing difference, an arena of dissent, from where prescriptive practices are questioned that affirm universalized models characterizing curriculum policies, a perspective that can be identified in the experience of structuring the curriculum of Education in Human Rights analyzed.

Key words: Education in human rights; Human Rights; curriculum policy; difference.

\section{Educación en Derechos Humanos: local de la diferencia}

Este estudio investiga la constitución del currículo de Educación en Derechos Humanos en Brasil, buscando identificar los sujetos con poder de significar el área y los sentidos en disputa en este proceso - notoriamente el modo como la diferencia se articula y construye consensos en estos espacios curriculares. Enfoca textos dirigidos a la formación continuada de educadores y a la formación de directrices curriculares de Educación en Derechos Humanos, producidos en función del proyecto implementado con el apoyo del Ministerio de la Educación. Argumenta a favor de asumir una noción de Derechos Humanos como espacio de expresión de la diferencia, arena de disensión, a partir del momento que se cuestionan las prácticas prescriptivas afirmativas de modelos universalizados que caracterizan políticas curriculares, perspectiva que puede ser identificada en la experiencia analizada de la constitución del currículo de Educación en Derechos Humanos.

Palabras claves: Educación en Derechos Humanos; Derechos Humanos; política curricular; diferencia 